\title{
Educação Ambiental e sustentabilidade social e ecológica dos lugares turísticos e de lazer
}

\author{
Environmental education and social and ecological \\ sustainability of tourist places and leisure
}

\author{
Solange Fernandes Soares Coutinho, Erica de Souza Silva, \\ Patrícia Alves da Silva
}

\section{RESUMO}

Considerando que a Educação Ambiental pode contribuir positivamente para a solução, minimização e prevenção de problemas ambientais, entre eles aqueles derivados do planejamento inadequado e da gestão equivocada de atividades de Turismo e de Lazer, este estudo, que faz parte de uma pesquisa da Coordenação de Estudos Ambientais da Fundação Joaquim Nabuco - "Dinâmicas Ecológicas e Sociais em Ambientes Costeiros do Nordeste Brasileiro: interações e intervenções" - objetiva discutir e provocar reflexões sobre complementaridades e conflitos entre turismo, lazer e meio ambiente, ressaltando o papel da Educação Ambiental para o alcance da sustentabilidade social, ecológica e econômica, através de análises qualitativas das atividades em questão. Baseou-se em um estudo de caso - o Município llha de Itamaracá, pertencente à Região Metropolitana do Recife, Estado de Pernambuco - centrando-se na revisão bibliográfica, observações de campo, levantamento, coleta e tratamento de dados secundários e primários, estes últimos obtidos através da aplicação de questionários semiabertos e histórias de vida. Metodologicamente, a análise de conteúdo permitiu a interpretação das respostas abertas. Os resultados alcançados demonstraram que no município estudado as atividades de Turismo e de Lazer são desenvolvidas de forma intensa, mesmo nos períodos de declínio, ocasionando modificações significativas nos ambientes que thes dão suporte devido à exploração massiva dos atrativos turísticos; ao fluxo desordenado de turistas, ocupantes de segundas residências, visitantes e excursionistas; à conduta inadequada em relação ao uso das praias e do patrimônio histórico-cultural; à ausência de planejamento e gestão pública e privada que integre uma Educação Ambiental abrangente e continuada às atividades de Turismo e de Lazer, garantindo-lhes sustentabilidade.

PALAVRAS-CHAVE: Educação Ambiental; Município llha de Itamaracá; Sustentabilidade Social e Ecológica; Turismo e Lazer. 


\section{ABSTRACT}

Considering that the Environmental Education can contribute positively to the solution, minimization and prevention of environmental problems, among them those derived of the inadequate planning and of the mistaken administration of activities of Tourism and of Leisure, this study, that it is part of a research of the Coordination of Environmental Studies of Fundação Joaquim Nabuco - "Ecological and Social Dynamics in Coast Sites of the Northeast of Brazil: interactions and interventions" - aims to discuss and to provoke reflections on complementarities and conflicts among tourism, leisure and environment, emphasizing the role of the Environmental Education to the reach of social, ecological and economical sustainability, through qualitative analyses of the activities in question. It's based on a case study - The Itamaracá Island Municipal District, belonging to the Metropolitan Area of Recife, State of Pernambuco - being centered in the bibliographical revision, field observations, rising, collects and treatment of secondary and primary data, these last ones obtained through the application of semiopened questionnaires and life stories. Methodologically, the analysis of content allowed the interpretation of the opened-answers. The reached results demonstrated that in the Municipal District studied the activities of Tourism and Leisure they are developed in an intense way, even in the decline periods, causing significant modifications in the environment that give them support due to the intensive exploration of tourist attractions; to the tourists' disordered flow, occupants of second residences, visitors and excursionists; to the inadequate conduct in relation to the use of the beaches and of the historical-cultural patrimony; to the planning and management absence of public and private administration that integrates an including and continuous Environmental Education to the Tourism and Leisure activities, guaranteeing them sustainability.

KEYWORDS: Environmental Education; Itamaracá Island Municipal District; Social and Ecological Sustainability; Tourism and Leisure.

\section{Considerações iniciais}

Uma mudança de paradigma faz-se necessária em pró da complexa noção de sustentabilidade social e ecológica frente aos intensos e graves impasses advindos do atual modelo de desenvolvimento. Dentre as atividades econômicas que mais se relacionam com o meio ambiente destacam-se o Turismo e o Lazer pela íntima relação que têm com as paisagens naturais e construídas. Tais atividades, segundo (COUTINHO; OLIVEIRA; SILVA, 2010, p.153-154),

Quando bem conduzidas, respeitando a capacidade de suporte do meio, os costumes e as necessidades do lugar, são capazes de trazer bons resultados para a economia local, para o bem estar e contribuir para a proteção do meio natural.

Para tanto, é imprescindível o cumprimento da legislação ambiental, como, por exemplo, o que recomenda a Política Nacional de Educação 
Ambiental: inserir a Educação Ambiental nos planos, programas e projetos voltados ao desenvolvimento das atividades de Turismo e de Lazer (BRASIL, 1999). Ressalta-se que o papel da Educação Ambiental está relacionado ao processo de construção do "exercício da cidadania por meio da participação ativa individual e coletiva, considerando os processos socioeconômicos, políticos e culturais que a influenciam" (PELICIONI; PHILIPPI JR, 2005, p.6).

Partindo desse pressuposto, o presente estudo buscou discutir e provocar reflexões sobre complementaridades e conflitos entre turismo, lazer e meio ambiente, ressaltando o papel da Educação Ambiental para o alcance da sustentabilidade social, ecológica e econômica, tendo como objetivos específicos: analisar a relação e contribuição da Educação Ambiental para o desenvolvimento das atividades de Turismo e de Lazer com sustentabilidade; verificar como a Educação Ambiental está inserida nos planos, programas e projetos direcionados ao desenvolvimento das atividades de Turismo e de Lazer no estudo de caso - Município Ilha de Itamaracá, Estado de Pernambuco; avaliar resultados das ações que relacionam atividades de Turismo e Lazer, Educação Ambiental e Sustentabilidade Social, Ecológica e Econômica através de análises qualitativas relativas aos promotores das atividades em questão, à população da área estudada, aos turistas, aos veranistas, aos excursionistas e aos visitantes.

Para o desenvolvimento desta pesquisa utilizou-se o estudo de caso de caráter qualitativo, centrado na análise de conteúdo, que teve na sua base a integração entre a pesquisa bibliográfica e documental e a pesquisa experimental, aliando as referências teóricas às observações e interpretações diretas dos fatos.

Foram realizadas pesquisa de campo, levantamento, coleta e tratamento de dados secundários e primários - aplicação de questionários semiabertos e levantamento de história de vida com representantes da população local (permanente), população temporária (ocupantes de segunda residência), turistas (hóspedes de hotéis ou pousadas) visitantes (visitantes de um dia em transportes particulares), excursionistas (visitantes de um dia em transportes coletivos), professores e gestores públicos do Município llha de Itamaracá.

\section{Aportes conceituais e relações entre turismo, lazer e Educação Ambiental na perspectiva da sustentabilidade social e ecológica}

O ser humano explora o meio do qual faz parte em uma relação intrínseca, na busca por experimentar novas sensações, com a curiosidade de encontrar algo ainda não visto, sentido ou explorado anteriormente, satisfazendo e/ou alimentando o desejo de querer ser, de saber e de fazer sempre mais. Este ciclo de procuras e conquistas é infinito pelo simples fato do ser humano ser inconcluso e estar sujeito às novas aprendizagens que se somam às experiências, sempre promovendo transformações. Entretanto, o interesse humano em explorar os diferentes ambientes passou de ser uma atividade integradora - desenvolvida para satisfazer suas verdadeiras necessidades -, para atender aos interesses econômicos que 
conduzem à exploração dos recursos naturais de forma desordenada e predatória, alterando, assim, o equilíbrio entre os elementos que constituem os diversos sistemas sociais e ecológicos. Neste sentido, Coutinho, Oliveira e Silva (2010, p.152) afirmam:

Os elementos que compõem os mais diferentes ambientes, sejam eles físicos, químicos ou biológicos, estão em constantes interações, possuindo, assim, interdependências diretas ou indiretas, o que origina dinâmicas próprias em ritmos a elas peculiares e estão sujeitas a alterações cíclicas ou acíclicas. Quando esses ambientes são alterados pela ação antrópica suas dinâmicas também o são, podendo as anteriores ser retomadas ou não, a depender da intensidade das intervenções e, ao mesmo tempo, da capacidade de recuperação do equilíbrio desses sistemas.

As atitudes referentes aos diversos usos do ambiente foram e ainda são predominantemente de máxima exploração e dominação, sendo que uma parcela significativa das atividades objetivava e objetiva a obtenção imediata do lucro (FERRETTI, 2002; PETROCCHI, 2009). Conforme Petrocchi (2009, p.27) "as agressões ambientais se multiplicaram em diversos setores, como industriais, agrícolas, na expansão urbana e também no turismo [...]" (grifo nosso).

Nas atividades de turismo e lazer "a degradação ambiental derivada da atividade reflete-se na mesma com graves efeitos negativos, gerando diminuição da arrecadação de divisas, podendo até extinguir localmente a atividade" (COUTINHO; SELVA, 2005, p.16). Tal fato pode ser evidenciado, teoricamente, no modelo de R. W. Buther (apud PETROCCHI, 2009, p.29) em que o local de destino antes pouco visitado é impulsionado pelo marketing, atraindo investimentos. Após isto, fazendo sucesso, predomina a exploração e busca pelo lucro em curto prazo, onde os serviços ecossistêmicos não são levados em consideração ou nem sequer são conhecidos, desvalorizando as potencialidades do lugar, o que contribui para a diminuição da produtividade turística, fazendo o destino entrar em decadência.

Para a Organização Mundial de Turismo (OMT),

O turismo compreende as atividades que realizam as pessoas durante suas viagens e estadas em lugares diferentes ao seu entorno habitual, por um período consecutivo inferior a um ano, com finalidade de lazer, negócio ou outras (apud DIAS, 2003, p.11).

Este fenômeno também é tratado por José Vicente de Andrade como um "complexo de atividades e serviços", serviços estes que envolvem "deslocamentos, transportes, alojamentos, alimentação, circulação de produtos típicos, atividades relacionadas aos movimentos culturais, visitas, lazer e entretenimento" (ANDRADE, 1997, p.22). Diferentemente do 
Turismo, o Lazer é algo que se pode fazer quando se possui tempo disponível sem a necessidade de ausentar-se do local da residência fixa por mais de vinte e quatro horas e que possa proporcionar diversão, prazer, como um passeio na praça em frente à residência habitual (PIRES, 2002).

O turismo como uma atividade econômica que gera renda e emprego transforma o meio no qual se dá em seus aspectos naturais e sociais. Requer, assim, não apenas investimentos, mas também, e principalmente, planejamento, gestão competente e monitoramento para atender às ofertas e necessidades do lugar. Ainda sob tal perspectiva, Lília Seabra (2003, p.154) afirma que:

O forte crescimento da atividade [turística], repercutindo no ambiente, na vida econômica, social e cultural das áreas receptoras, gerando impactos de qualidade e quantidade diversos, colocou o turismo, nos últimos tempos, como tema prioritário na pauta de preocupações de planejadores, acadêmicos e gestores de políticas públicas, interessados na temática.

Segundo Mário Pires (2002, p.4): "[...] o turismo é uma atividade que, em muitos pontos, comporta-se como qualquer outra, exigindo investimentos e política intensiva". Entretanto, concorda-se com as considerações a seguir:
É fundamental capacitar-se para planejar o turismo e oferecer um turismo do melhor nível, e ao mesmo tempo, sensibilizar os turistas, excursionistas e visitantes a não desenvolverem atividades predatórias que possam afetar negativamente o lugar e seus habitantes e comprometer a sustentabilidade da atividade. (COUTINHO; SELVA, 2005, p.6).

$\mathrm{Na}$ busca pela sustentabilidade das atividades de turismo e lazer destaca-se o papel da Educação, e em especial, à voltada para o meio ambiente - a Educação Ambiental -, como principal instrumento de condução a mudanças de valores humanos em relação ao meio natural e construído, pois esta contribui de forma significativa para que a espécie humana perceba-se como parte integrante dos sistemas ecológicos, com direitos e deveres em relação à qualidade do ambiente em que direta ou indiretamente interfere.

A Lei Federal no 9.795 de 1999 que instituiu a Política Nacional de Educação Ambiental (PNEA) define a Educação Ambiental como:

[...] o processo por meio do qual o indivíduo e a coletividade constroem valores sociais, conhecimentos, habilidades, atitudes e competências voltadas para a conservação do meio ambiente, bem de uso comum do povo, essencial à sadia qualidade de vida e sua sustentabilidade (BRASIL, 1999).

É dever dos representantes do poder público contemplar a Educação Ambiental como um componente essencial e permanente da educação 
nacional, instituída pela Lei 9.795/99 e regulamentada pelo Decreto 4.281/02 (BRASIL, 1999; BRASIL, 2002). A PNEA ressalta no seu Art. 2o que a Educação Ambiental deve estar presente de forma articulada em todos os níveis e modalidades no processo educativo, contemplando o ensino formal, não formal e informal, uma vez que a população local pode promover, de forma significativa e direta, a degradação dos ambientes por não ser orientada em relação ao uso adequado dos ambientes ou apenas por perceber os recursos naturais apenas como objetos de lucro crescente.

A responsabilidade de inserir a Educação Ambiental nos planos, programas e projetos desenvolvidos é, antes de tudo, do Poder Público Municipal. As secretarias de Educação, Esporte, Cultura e de Turismo devem contemplá-la em suas atividades. No entanto, muitas vezes quando é realizada isto se dá de forma inadequada em eventos pontuais e desconectados criando, inclusive, conflitos entre esses setores administrativos ou outros.

\section{A contribuição da Educação Ambiental para sustentabilidade dos ambientes que dão suporte às atividades de turismo e de lazer no município llha de Itamaracá (PE)}

O Município Ilha de Itamaracá está localizado no Litoral Norte do Estado de Pernambuco; apresenta área de $65,41 \mathrm{~km}^{2}$ e integra a Região Metropolitana do Recife. Segundo a contagem do Instituto Brasileiro de Geografia e Estatística (IBGE), em 2010 a população era de 22.449 habitantes. A maioria dos habitantes ocupa a área urbana, 17.521, e apenas 4.928 residia na área rural (BRASIL, 2011). O acesso à llha se dá através da Ponte Getúlio Vargas, BR 101 e PE 35. O Canal de Santa Cruz, que apresenta $22 \mathrm{~km}$ de extensão, separa a llha do continente e representa um dos mais importantes complexos estuarinos do Estado de Pernambuco. Todo o município está localizado no interior da Área de Proteção Ambiental (APA) Santa Cruz que corresponde a uma Unidade de Conservação criada pelo Governo do Estado de Pernambuco em 17 de outubro de 2008, através do Decreto 32.488 (PERNAMBUCO, 2010).

A Ilha de Itamaracá oferece diversos atrativos turísticos naturais, históricos e culturais que dão essência às atividades de turismo e lazer, como mostra o inventário turístico do Estado de Pernambuco elencado pela Empresa Pernambucana de Turismo (Empetur) no ano de 2008 (PERNAMBUCO, 2008).

Entretanto, em torno de uma década atrás as atividades de turismo e de lazer sofreram forte retrocesso na Ilha em função da presença de presídios, inclusive um semiaberto, mesmo lá havendo uma grande quantidade de segundas residências face à proximidade da capital pernambucana, $47 \mathrm{~km}$. A condição de insegurança levou muitos proprietários a venderem seus imóveis ou a não mais utilizá-los, enquanto hotéis e pousadas tiveram suas ocupações reduzidas. Hoje há uma diminuição da quantidade de presidiários, a perspectiva dos presídios de lá saírem e investimentos na promoção do turismo e do lazer na llha, o que já tem gerado reaquecimento dessas atividades, sem o município ter se organizado para isto. 
Segundo o Secretário de Turismo, Indústria, Comércio, Esporte e Cultura da Prefeitura Municipal da llha de Itamaracá, as atividades de turismo e de lazer estão, de fato, retomando o lugar que ocuparam no passado. A instalação da Casa Globo Verão, da Rede Globo Nordeste de Televisão, no Bairro do Forte Orange é, segundo ele, uma iniciativa do Governo do Estado por conta da demanda da população e tem o objetivo de desafogar o Litoral Sul qualificando o Litoral Norte pernambucano para receber turistas. Um dado que pode contribuir para 0 respaldo desse raciocínio é que a população do Município sofreu um acréscimo de 6.591 habitantes segundo o Censo Populacional realizado pelo IBGE no ano de 2010 (BRASIL, 2011).

Ao aplicar o questionário na área objeto de estudo se percebeu diferentes opiniões acerca do desenvolvimento das atividades de turismo e lazer; do comportamento da população em relação à utilização das praias; do reconhecimento de algum problema ambiental apontando as causas, os agentes e as consequências para o turismo e lazer; do conhecimento de iniciativas de Educação Ambiental relacionada ao turismo e ao lazer que foi ou está sendo desenvolvida na llha de Itamaracá e até da própria relação entre Educação Ambiental, Turismo e Lazer.

Foram realizadas sessenta e uma entrevistas no Município, sendo quinze no Bairro do Forte Orange, quinze no de Jaguaribe, quinze também no de Pilar e onze no de Sossego, direcionadas à população local (permanente), população temporária (segunda residência), turistas (hóspede de hotel ou pousada) visitantes (visitante de um dia em transporte particular), excursionistas (visitante de um dia em transporte coletivo), professores e mais cinco com gestores municipais.

Em relação às mudanças nas atividades de Turismo e Lazer, todos os entrevistados responderam que está acontecendo algo de diferente relatando que houve um aumento no fluxo de turistas devido às ofertas e atividades desenvolvidas na llha. O Diretor de Esporte relatou que a llha "voltou a ser um dos polos turísticos com força devido ao aumento da quantidade das atividades náutico-esportiva". Nesta mesma ótica, o Secretário de Agricultura, Pesca e Meio Ambiente afirmou que as mudanças nas atividades de Turismo e Lazer ocorrem devido à "exploração diferenciada nas praias como a maratona de velas e canoagem".

O Diretor de Cultura mencionou que as mudanças ocorridas nas atividades de turismo e de lazer e o aumento do fluxo do turismo na llha ocorrem devido ao "planejamento em longo prazo e a produção de eventos que estimulam o turismo cultural, além do fortalecimento dos atrativos culturais, como monumentos históricos e o apoio às manifestações culturais". Já a Coordenadora Pedagógica afirmou que as mudanças nas atividades de Turismo e de Lazer acontecem porque,

\footnotetext{
Está sendo feito um trabalho que está tirando a impressão de abandono e sujeira. A secretaria de Meio Ambiente está fazendo um trabalho de revitalização das praias [...]. Em relação ao turismo está tendo maior visitação das pessoas que há tempos atrás se afastaram.
} 
No entanto, durante a pesquisa de campo e ao analisar as entrevistas percebeu-se que o aumento no fluxo de turistas, visitantes e excursionistas nas praias da llha e a grande movimentação de veículos vêm ocorrendo sem a oferta de uma estrutura adequada, acarretando modificações significativas nos ambientes e o surgimento de diversos problemas ambientais que prejudicam o desenvolvimento das atividades de turismo e de lazer. De acordo com a reportagem publicada do Jornal do Commercio ${ }^{1}$, desde o mês de Novembro do ano de 2010 a llha tem sido (re)admirada pelos turistas e ao mesmo tempo sofrido com o grande acúmulo populacional e o descuido em relação à conservação e à fiscalização dos patrimônios naturais e históricos ali presentes. Durante o verão, a situação se agrava com a grande movimentação dos ônibus que conduzem excursionistas para atividades de Lazer. Segundo matéria publicada da Folha de Pernambuco ${ }^{2}$, a llha de Itamaracá cresceu de forma desordenada e agora sofre na busca de soluções com o objetivo de transformar o local em um refúgio para o sossego dos pernambucanos.

O desenvolvimento destas atividades requer uma atenção especial por parte dos gestores públicos dos diferentes setores no momento em que o grande fluxo de pessoas nas praias demanda infraestrutura adequada para que possa acomodar durante curtas temporadas um número bem maior de pessoas em relação à população fixa. Neste contexto, de acordo com Reinaldo Dias (2003, p.10),

\begin{abstract}
Nos deslocamentos provocados pela atividade turística, vão sendo geradas necessidades - de transporte, alojamento, acomodação, equipamentos, vestuário etc. - que provocam o surgimento de numerosos negócios, de modo geral de pequenos e médios portes, para o atendimento dos turistas.
\end{abstract}

No Bairro do Forte Orange, $60 \%$ dos entrevistados responderam que está se dando algo de diferente devido ao aumento do fluxo de turistas na Ilha por conta da presença da Casa Globo Verão. Já no de Jaguaribe, aproximadamente $47 \%$ dos entrevistados afirmaram que está se dando algo diferente apontando como fatores o maior fluxo de turistas e a presença da Casa Globo Verão, como relatou a entrevistada JE13 "as pessoas estão indo para as praias que oferecem mais coisas, shows, brincadeiras, espaço para as crianças brincar". Apenas um entrevistado afirmou que 0 fechamento do Forte Orange, patrimônio histórico de significativa representatividade, influenciou no afastamento dos turistas (Tabela 1).

No Bairro do Pilar $53 \%$ dos entrevistados afirmaram estar acontecendo algo de diferente. Alegaram que a prefeitura está investindo, devido à construção de uma praça no centro da avenida principal e por conta das festividades oferecidas nos fins de semana, assim como a presença do Centro Nacional de Pesquisa e Conservação de Mamíferos Aquáticos na Ilha, o que atrai mais turistas, visitantes e excursionistas. 
Tabela 1: Dados referentes aos resultados da análise quantitativa de acordo com as questões selecionadas.

Table 1: Data regarding the results of the quantitative analysis according to selected questions.

\begin{tabular}{|c|c|c|c|c|c|c|c|c|c|c|c|c|c|c|c|c|}
\hline \multirow[t]{2}{*}{ BAIRROS } & \multicolumn{4}{|c|}{$\begin{array}{c}\text { Em relação ao Turismo } \\
\text { e ao Lazer na llha de } \\
\text { Itamaracá, acha que } \\
\text { está acontecendo algo } \\
\text { diferente? }\end{array}$} & \multicolumn{4}{|c|}{$\begin{array}{c}\text { Você acha que existe } \\
\text { relação entre } \\
\text { Educação Ambiental, } \\
\text { Turismo e Lazer? }\end{array}$} & \multicolumn{4}{|c|}{$\begin{array}{c}\text { Você reconhece } \\
\text { algum problema } \\
\text { ambiental na llha de } \\
\text { Itamaracá? }\end{array}$} & \multicolumn{4}{|c|}{$\begin{array}{c}\text { Você conhece alguma } \\
\text { iniciativa de Educação } \\
\text { Ambiental relacionada ao } \\
\text { Turismo e ao Lazer que } \\
\text { foi ou está sendo } \\
\text { desenvolvida na Ilha de } \\
\text { Itamaracá? }\end{array}$} \\
\hline & $\mathrm{S}$ & $\%$ & $\mathrm{~N}$ & $\%$ & $\mathrm{~S}$ & $\%$ & $\mathrm{~N}$ & $\%$ & $\mathrm{~S}$ & $\%$ & $\mathrm{~N}$ & $\%$ & $\mathrm{~S}$ & $\%$ & $\mathrm{~N}$ & $\%$ \\
\hline Jaguaribe & 7 & 47 & 8 & 53 & 15 & 100 & - & - & 9 & 60 & 6 & 40 & 4 & 27 & 11 & 73 \\
\hline Pilar & 8 & 53 & 7 & 47 & 13 & 87 & 2 & 13 & 10 & 67 & 5 & 33 & 3 & 20 & 12 & 80 \\
\hline $\begin{array}{c}\text { Forte } \\
\text { Orange }\end{array}$ & 9 & 60 & 6 & 40 & 13 & 87 & 2 & 13 & 11 & 73 & 4 & 27 & - & - & 15 & 100 \\
\hline Sossego & - & - & 11 & 100 & 10 & 91 & 1 & 9 & 8 & 73 & 3 & 27 & - & - & 11 & 100 \\
\hline $\begin{array}{c}\text { Total } \\
56 \\
\end{array}$ & 24 & $43 \%$ & 32 & $57 \%$ & 51 & $91 \%$ & 5 & $9 \%$ & 38 & $68 \%$ & 18 & $32 \%$ & 20 & $36 \%$ & 36 & $64 \%$ \\
\hline
\end{tabular}

Dos entrevistados, $47 \%$ no Bairro do Pilar, $53 \%$ em Jaguaribe e $40 \%$ no Bairro do Forte Orange afirmaram não está acontecendo nada de diferente em relação ao Turismo e ao Lazer. Relataram que a llha está abandonada e que não há investimentos. A entrevistada PPL2 disse que "as mesmas coisas acontecem no verão há anos, e quando acaba o mês de janeiro e fevereiro tudo volta ao normal'.

Dos entrevistados no Bairro do Sossego, 100\% afirmaram que nada de diferente em relação às atividades de turismo e de lazer está acontecendo. Os principais motivos foram: a dificuldade de acesso à praia, pois é feito por uma estrada que não é asfaltada ou pelo Rio Jaguaribe, mas dependendo do horário a travessia torna-se perigosa pela falta de segurança. Também não há um lugar para lazer, para se divertir, como relata a entrevistada ST7 "dependendo da época, há menos pessoas nas praias. Mesmo assim, aqui em Sossego tem pouca movimentação em relação às outras praias de Itamaracá".

A segunda questão colocada para os entrevistados foi se existe relação entre Educação Ambiental, Turismo e Lazer. Em relação a ela, em síntese os entrevistados externaram que a Educação Ambiental contribui para um melhor desempenho das atividades de turismo e lazer, pois propicia a proteção dos ambientes oferecendo melhor qualidade de uso desses espaços; que a Educação Ambiental transforma as atitudes humanas conduzindo à valorização do meio em que vive, educando as pessoas para cuidar bem do lugar que faz parte, contribuindo para a conservação das praias e outros ambientes, porque só quando as pessoas possuem educação cuidam dos ecossistemas, pois do mesmo jeito que os ambientes precisam ser conhecidos também precisam ser protegidos. Se a população degrada o ambiente, afeta diretamente o turismo e quaisquer atividades desenvolvidas neste meio.

No Bairro do Forte Orange, $87 \%$ dos entrevistados responderam que existe relação entre Educação Ambiental, Turismo e Lazer alegando que com a Educação Ambiental as pessoas aprendem a utilizar de forma adequada as praias e desenvolvem atividades de turismo e lazer sem 
degradar o ambiente. Como exemplos apontaram a manutenção das praias limpas, a educação da população e daí a conscientização das pessoas para cuidar do ambiente. O entrevistado FV12 destacou que "quando se é educado, aproveita-se melhor o ambiente e também o ambiente apresenta melhor qualidade".

No Bairro do Sossego, 91\% dos entrevistados disseram que existe relação entre educação ambiental, turismo e lazer ressaltando ser necessária a educação e reeducação das pessoas para conservação das praias e proteção dos ambientes, como relata a entrevistada SP6 "para existir o turismo e o lazer tem que ter a educação ambiental'. Complementando, destaca-se o relato da entrevistada SV11,

O turismo só poderia acontecer se as pessoas tivessem preparadas para usar o ambiente, mas o que acontece é que cada vez mais as pessoas não se importam em cuidar das coisas que usam, não ligam porque não moram aqui. Assim quem se prejudica mais são os moradores [...] e as pessoas que visitam as praias.

No Bairro de Jaguaribe, $100 \%$ dos entrevistados afirmaram que existe relação entre Educação Ambiental, Turismo e Lazer apontando a educação e a consciência das pessoas no cuidado com a natureza como requisitos à conservação e à preservação do ambiente. Foi o que revelou a entrevistada JPL1. Segundo ela "a educação ambiental faz as pessoas utilizar as praias, aproveitar e se divertir com a família sem destruí-las, sem sujar, sem degradar as praias. Assim, com a praia mais conservada os turistas vêm mais vezes".

No Bairro do Pilar, $87 \%$ dos entrevistados afirmaram que existe relação entre Educação Ambiental, Turismo e Lazer, apontando como exemplo dessa relação a existência de uma educação voltada para a proteção da qualidade das áreas exploradas e que com educação ambiental as pessoas passam a respeitar mais os ambientes que utilizam. Dos entrevistados, apenas 13\% nos bairros de Forte Orange e Pilar, e $9 \%$ no de Sossego afirmaram não existir relação entre Educação Ambiental, Turismo e Lazer, mas não justificaram suas respostas.

Percebe-se que a população reconhece a importância da Educação Ambiental no desenvolvimento das atividades de turismo e de lazer, como afirma a entrevistada PP15 "o ambiente depende da educação das pessoas. A gente não pode pensar em promover eventos sem educar as pessoas".

A Coordenadora Pedagógica disse que a Secretaria de Educação desenvolve trabalhos que relacionam o Turismo e Lazer à Educação Ambiental porque "a Educação Ambiental já é uma das disciplinas do currículo no Município. Nas escolas há inserção da Educação Ambiental'. O Secretário de Turismo afirmou que a Secretaria desenvolve trabalhos que relacionam Turismo, Lazer e Educação Ambiental em parceria com a Secretaria de Meio Ambiente e que "são desenvolvidas ações de conscientização com a população com objetivo de reeducar o pessoal'. 
Ao realizar as entrevistas com professores em quatro escolas do Município, foi possível registrar que a Educação Ambiental não foi implementada em todas as escolas, nem em todas as séries como recomenda a Política Nacional de Educação Ambiental. As professoras ainda afirmaram que a prefeitura prometeu a realização de campanhas nas escolas em relação à Educação Ambiental, mas até o momento não foram realizadas, assim como outros projetos que também foram prometidos à população.

No questionário aplicado também foi possível analisar o conhecimento dos gestores públicos em relação à contribuição da Política Nacional de Educação Ambiental. O Diretor de Esporte não respondeu à questão, mas alertou que "o governo poderia fazer uma parceria com as secretarias para que ambas tenha o conhecimento das questões ambientais". Já o Secretário de Turismo afirmou que "Itamaracá é um município que tem $90 \%$ do território inserido no contexto da sustentabilidade ambiental. Todas as ações seguem a risca as leis do meio ambiente". O Diretor de Esporte relatou que a Educação Ambiental "valoriza o esporte como um todo", enquanto o Diretor de Cultura afirmou que através da Educação Ambiental pode-se ter "a consciência ambiental para com os patrimônios públicos, praças e escolas". O Secretário de Meio Ambiente relatou que "quando se trata de Educação Ambiental começamos a ver os bons frutos". A Coordenadora Pedagógica falou o seguinte:

\begin{abstract}
Aqui em Itamaracá têm-se o caso da pesca, da agricultura. Embora algumas pessoas não tenham a consciência de vida, a partir do momento em que você dá a sustentabilidade dos ambientes, a produção melhora e a qualidade de vida também.
\end{abstract}

Ainda afirmou que "a política é como um leque abrange várias questões ambientais, direciona a política local em limitar o uso dos recursos, de uma forma eficiente". O Secretário de Turismo, Indústria, Comércio, Esporte e Cultura, disse que "pelo conhecimento que tenho, ela tem toda uma inserção no apoio e aporte financeiro que a prefeitura precisa como suporte e subsídio para efetivar os projetos de grande porte no município".

O Diretor de Cultura afirmou que a PNEA contribui "não somente com as questões ambientais, mais integra também as secretarias de saúde e de infraestrutura". Ainda, segundo ele: "a Educação Ambiental integrada contribui para a sustentabilidade das políticas. A Política Nacional de Educação Ambiental precisa ser integradora e transversal para ser eficiente".

O Secretário de Meio Ambiente afirmou que a Política Nacional de Educação Ambiental contribui no momento em que "recentemente na grade curricular das escolas foi implementada a Educação Ambiental. Um trabalho que começa nas escolas e depois nas ruas educando as pessoas". Complementando, disse que a Secretaria desenvolve diversas ações relativas à Educação Ambiental, como: "oficinas de reciclagem na orla de Jaguaribe com materiais oriundos da natureza com os alunos das escolas, 
limpeza da orla, trilha ecológica e atividades que façam as crianças se conscientizar". E como resultados positivos foram apontados a diminuição do lixo nas ruas, o respeito aos horários quanto à passagem do caminhão de coleta de lixo e a coleta seletiva nas escolas.

O Secretário de Meio Ambiente afirmou que em 2010 realizou uma parceria com a Empetur da qual relatou o seguinte:

Foi realizado um curso de ecoturismo com jovens da comunidade, trabalhando também nas escolas, campanhas e palestras com o objetivo de promover a sustentabilidade dos ambientes. Este ano vamos repetir o curso, normalmente fazemos palestras com o auxílio de um professor especializado em educação ambiental para elaborar oficinas nas escolas municipais e estaduais.

E como resultado positivo relatou que "as pessoas estão mais educadas, se conscientizando mais com estes trabalhos desenvolvidos nas escolas e na comunidade, a redução do lixo é um fator significativo".

Comparando as opiniões dos representantes municipais, os depoimentos revelam que, de uma maneira geral, estes não possuem o conhecimento necessário em relação ao conceito e à prática da Educação Ambiental, assim acabam desenvolvendo projetos que degradam o meio ambiente causando impactos negativos pela ausência de conhecimento em relação às questões ambientais que advêm de usos e manejos inadequados dos recursos naturais. Neste caso, percebe-se a importância do conhecimento dos gestores públicos em relação à Educação Ambiental para o desenvolvimento de planos, programas e projetos voltados às atividades de Turismo e Lazer, uma vez que a responsabilidade para tal é, especialmente, do poder público local, competindo às Secretarias de Educação, Esporte, Cultura e Turismo também contemplá-la nas suas atividades de forma integrada e contínua. No entanto, na maioria das vezes ela é realizada de maneira pontual e desconectada das realidades e necessidades do lugar, quando não é sequer mencionada.

A questão 3 do instrumento de coleta de dados primários objetivava verificar se os respondentes identificavam os problemas locais, suas causas e agentes, e os relacionavam com o Turismo e o Lazer no Município.

O despejo de lixo nas praias, vias públicas e em terrenos baldios provoca a degradação dos solos e dos recursos hídricos superficiais e subterrâneos, além da proliferação de insetos transmissores de doenças. Dos entrevistados no Bairro do Pilar, 67\% reconheceram a existência de problemas ambientais, no Bairro de Jaguaribe $60 \%$, no de Forte Orange e Sossego $73 \%$. Os entrevistados apontaram como principal causa da deposição inadequada do lixo nas praias a falta de educação da população e dos visitantes que utilizam as praias para desenvolver atividades de turismo e lazer, uma vez que a prefeitura do município está realizando uma ação de revitalização da Orla da Ilha de Itamaracá, disponibilizando lixeiras fixas. Esta medida foi observada apenas na Praia de Jaguaribe e na Praia 
de Sossego ao longo da faixa de areia, assim como a conservação dos barcos que enfeitam a praia e o ordenamento das barracas para que a população aproveite mais o espaço, além da limpeza da Orla com caminhões da prefeitura na Praia do Forte Orange.

Ainda em relação aos problemas ambientais, foram apontadas como causas a falta de saneamento em função da precariedade das fossas sépticas, da rede de esgoto, da coleta do lixo e da distribuição de água encanada; a ineficiência da fiscalização e o pouco interesse da prefeitura do município para solucioná-los. Outro problema mencionado pelos entrevistados foi a presença de animais e de veículos ao longo da faixa da areia da praia, responsabilizando a população local, turistas e veranistas em função da ausência de educação e de higiene dos mesmos. Entretanto, os mais destacados foram: aterro dos manguezais por conta da especulação imobiliária, contaminação dos recursos hídricos que teve como principais causas citadas a deposição inadequada do lixo, a presença de animais domésticos nos corpos d'água, esgotos a céu aberto e ausência de fiscalização para, por exemplo, orientar e se necessário punir os donos de peixarias que descartam as vísceras e escamas dos peixes em locais não apropriados, acarretando a proliferação de moscas e o mau cheiro que se agrava quando chove.

A ausência de fossas sépticas foi observada em grande parte das ruas do Pilar, além de ser uma derivação da insuficiência de investimento da Prefeitura do Município, se agrava ainda mais pela falta de educação dos moradores locais que não respeitam nem suas próprias condições de higiene e lançam os dejetos nas ruas, contribuindo para a degradação do solo e da água, e a exalação de mau cheiro, além de provocar a proliferação de vetores patogênicos por diversos tipos de veiculação.

Durante apenas uma das visitas de campo observou-se quatro animais domésticos a solta na orla, o que pode causar poluição das águas e do solo a partir de fezes e urina que entram em contato com a areia e a água contaminando os banhistas e outras pessoas que circulam no local. Isto se agrava em função da falta de educação das pessoas que frequentam as praias, especialmente nos finais de semana durante as férias de verão quando o número delas é bem maior, o que acaba interferindo negativamente na qualidade de vida da população local e nas atividades de Turismo e Lazer.

No Bairro do Sossego, $73 \%$ dos entrevistados afirmaram que lá existem problemas ambientais, relatando como uma das principais causas a falta de interesse da prefeitura para realizar o saneamento básico e calçamento da estrada. Enfim, destacaram a precariedade da infraestrutura, como a seguir revela a respondente DPL3:

Há uma polêmica na construção da estrada, os veranistas não querem porque alegam que com a construção da estrada vai vir marginal e acabar com Sossego, mas eles não precisam daqui, só vem em época de verão. Era para beneficiar os nativos que moram aqui e precisam da estrada. O calçamento traria benefícios inúmeros pra Sossego. 
Um dos benefícios apontados foi a atual existência de uma ambulância para servir a comunidade. Todos os problemas ditos como ambientais citados pelos entrevistados dos bairros de Forte Orange, Pilar, Jaguaribe e Sossego foram apontados como causas do afastamento dos turistas e demais pessoas que gostam dos ambientes de praias, por conta do mau uso desses espaços. No caso da Praia de Sossego, o afastamento dos turistas também foi relacionado à dificuldade de acesso à praia. Dos entrevistados que alegaram não reconhecer nenhum problema ambiental, $33 \%$ são do Bairro de Pilar, em Jaguaribe $40 \%$, em Sossego $27 \%$ e em Forte Orange $27 \%$. De uma forma geral afirmaram que o ambiente está em boas condições e que a prefeitura está investindo aos poucos.

Em relação a quarta e última questão posta, os entrevistados afirmaram que não conhecem nenhuma iniciativa de Educação Ambiental relacionada ao Turismo e ao Lazer que foi ou está sendo desenvolvida na Ilha de Itamaracá nas seguintes proporções: nos bairros de Sossego e Forte Orange $100 \%$, Jaguaribe $73 \%$ e Pilar $80 \%$. Os entrevistados disseram que devem existir iniciativas de Educação Ambiental relacionadas ao Turismo e ao Lazer na Ilha para alertar e orientar os turistas e visitantes de qualquer ordem. A entrevistada SV11 relatou que:

Deveria investir em um tipo de programa voltado para cuidar melhor das praias, para saber usar e conhecer mais sobre o ambiente que usamos durante todo o ano e não apenas nas férias, até porque as pessoas não vêm pra cá só nas férias.

No Bairro do Forte Orange os entrevistados responderam que devem existir iniciativas de Educação Ambiental relacionada ao Turismo e ao Lazer na Ilha de Itamaracá, como relata a entrevistada FPT6 "Iniciativa sim, de qualidade, mas não adianta iniciar e não continuar [...]".

No Bairro do Pilar $20 \%$ dos entrevistados afirmaram conhecer iniciativas de Educação Ambiental relacionada ao Turismo e ao Lazer, destacando as ações realizadas pela Prefeitura do Município, como a frequente coleta de lixo e limpeza de resíduos sólidos nas praias, a colocação de coletores de lixo nas praias, a organização das barracas e a distribuição de sacolas na orla para os turistas e visitantes recolherem o lixo que produzem e darem a ele o destino correto. De acordo com a entrevistada PE12, a distribuição de sacolas na orla do Pilar foi uma ação que só aconteceu durante um mês. Em relação ao reordenamento das barracas, a entrevistada PV9 afirmou que esta ação "evita a má impressão e as pessoas cuidam melhor da praia".

Como já citado, dos entrevistados do Bairro do Pilar $80 \%$ afirmaram que não conhecem nenhuma iniciativa de Educação Ambiental relacionada ao Turismo e ao Lazer que foi ou está sendo desenvolvida na llha, mas que deveria existir, como menciona a entrevistada PT8: 
Para ajudar a melhorar o ambiente que usamos e para as pessoas se educar [...] ensinar as pessoas a usar direito as praias, colocar pessoas olhando os turistas como guias e ensinando a gente a cuidar melhor das praias que usamos.

Em Jaguaribe, $27 \%$ dos entrevistados afirmaram conhecer iniciativas de Educação Ambiental relacionadas ao Turismo e ao Lazer na llha de Itamaracá também destacando as ações realizadas pela prefeitura do município, como demonstra a fala da entrevistada JPL1 "há aproximação das pessoas da prefeitura com a população. Agora eles têm mais contato com a gente e respeitam muito os moradores, querem saber o que está acontecendo".

Desta forma observou-se que a população entrevistada tem o conhecimento de que é necessário as pessoas se reeducarem para que utilizem os atrativos turísticos e de lazer de forma adequada, no que muito pode contribuir positivamente a Educação Ambiental por meio de programas e projetos que sensibilizem as pessoas para a importância dos recursos naturais serem utilizados de maneira sustentável, uma vez que a Educação Ambiental é um instrumento que possibilita mudanças de valores do ser humano em relação ao meio natural e construído, de forma que o faça perceber-se como um dos responsáveis pela qualidade ambiental - uma necessidade à solução, à minimização e à prevenção dos problemas ambientais derivados de atividades mal planejadas e/ou inadequadamente gerenciadas.

\section{Considerações finais}

Pelo exposto conclui-se que a Educação Ambiental pode vir a contribuir para a sustentabilidade social e ecológica dos ambientes que dão suporte às atividades de Turismo e de Lazer quando é inserida de forma eficaz, oferecendo à população local, aos veranistas, aos visitantes, aos excursionistas e aos turistas orientações em relação ao uso devido dos ambientes no desenvolvimento das atividades em questão, garantindo as dinâmicas necessárias à proteção dos recursos naturais e construídos. No entanto, na llha de Itamaracá estas atividades estão sendo desenvolvidas sem a necessária atenção às alterações relativas à qualidade dos ambientes que dão suporte às mesmas.

A partir de um intenso e contínuo processo de construção conjunta da Educação Ambiental o ser humano poderá compreender que a diversidade ecológica dos ecossistemas está direta ou indiretamente dependente do modo de exploração dos ambientes tornando-se mais sensível para com as questões ambientais e, por consequência, adotando valores e práticas sustentáveis - 0 que se dá através de hábitos e ações na relação do ser humano com o ambiente do qual faz parte.

Através da Educação Ambiental os próprios moradores do lugar podem contribuir para o monitoramento das atividades de Turismo e de Lazer, condição indispensável à sustentabilidade ecológica e social dos ambientes que lhes dão suporte e para o bem estar da população local. 
Em síntese, para que as atividades de Turismo e Lazer sejam desenvolvidas de forma sustentável torna-se imprescindível que a Educação Ambiental abranja os diversos atores e setores de maneira contínua, uma vez que o ambiente que é utilizado como suporte para o desenvolvimento destas atividades necessita de uma atenção especial de proteção dos recursos naturais e, mais que qualquer outra coisa, da educação das pessoas que os utilizam para fins econômicos no momento em que o atual modelo de desenvolvimento intensifica cada vez mais o consumo à medida que as intensas explorações dos recursos naturais oferecem bons lucros.

Sendo assim, torna-se importante a intervenção do poder público municipal que tem como dever implementar políticas públicas voltadas à conservação dos patrimônios naturais, históricos culturais e arquitetônicos, fato este ainda incipiente no Município Ilha de Itamaracá. Observou-se que grande parte dos gestores municipais não possui o conhecimento necessário sobre a Política Nacional de Educação Ambiental e, assim, estes ficam limitados quando necessitam desenvolver projetos que relacionem, de fato, a Educação Ambiental ao Turismo e ao Lazer.

\section{Referências bibliográficas}

ANDRADE, J.V. Turismo: fundamentos e dimensões. São Paulo: Ática, 1997.

BRASIL, Instituto Brasileiro de Geografia e Estatística (IBGE). Cidades@. 2011. Disponível em: http://www.ibge.gov.br/cidadessat/topwindow.htm?1. Acesso em: 17 maio 2011.

BRASIL. Presidência da República. Decreto № 4281, de 25 de junho de 2002 que regulamenta a Política Nacional de Educação Ambiental. Brasília: DOU, 2002.

BRASIL. Lei № 9.795, de 27 de abril de 1999 que instituiu a Política Nacional de Educação Ambiental. Brasília: DOU, 1999.

COUTINHO, S.F.S.; OLIVEIRA, D.C.; SILVA, P.A. Alterações das Dinâmicas Ecológicas e Sociais Derivadas do Turismo e do Lazer no Litoral Norte do Estado de Pernambuco, Região Nordeste do Brasil. In: SEABRA, G.; SILVA, J.A.N.; MENDONÇA, I.T.L. (org.) A conferência da terra: aquecimento global, sociedade e biodiversidade. V. III. João Pessoa: Editora Universitária da UFPB, 2010. Disponível em: <http://www.mediafire.com/?izexz2mymmn>. Acesso em: 3 de julho 2011.

COUTINHO, S.F.S.; SELVA, V.S.F. Turismo e desenvolvimento local. Fortaleza: Semace, 2005.

DIAS, R. Turismo sustentável e meio ambiente. São Paulo: Atlas, 2003.

FERRETTI, E.R. Turismo e meio ambiente. São Paulo: Roca, 2002.

PELICIONI, M.C.F.; PHILIPPI JR, A. Bases Políticas, Conceituais, Filosóficas e Ideológicas da Educação Ambiental. In: PHILIPPI JR, A.; PELICIONI, M.C.F. (org). Educação ambiental e sustentabilidade. São Paulo: Manole, 2005. 
PERNAMBUCO. Agência Estadual de Meio Ambiente e Recursos Hídricos. Unidades de Conservação. Recife: $\mathrm{CPRH}$, 2010. Disponível em: http://www.cprh.pe.gov.br/home. Acesso em: 14 fev. 2011.

PERNAMBUCO. Empetur, Empresa Pernambucana de Turismo. Inventário turístico de Pernambuco. 2008. (CD-R).

PETROCCHI, M. Turismo: planejamento e gestão. 2. ed. São Paulo: Pearson Prentice Hall, 2009.

PIRES, M. J. Lazer e turismo cultural. 2. ed. São Paulo: Manole, 2002.

SEABRA, L. Turismo sustentável: planejamento e gestão. In: CUNHA, S.B.; GUERRA, J.T. (org). A questão ambiental: diferentes abordagens. Rio de Janeiro: Bertrand Brasil, 2003.

\section{Notas:}

${ }^{1}$ Jornal em circulação da Região Metropolitana do Recife, matéria publicada no dia 17/01/2011 na Coluna de Cidades, p.8.

2 Jornal em circulação da Região Metropolitana do Recife, matéria publicada no dia 16/01/2011 na Coluna Grande Recife, p.3-4.

Solange Fernandes Soares Coutinho: Fundação Joaquim Nabuco e Universidade de Pernambuco, Recife, PE, Brasil.

E-mail: solange.coutinho@fundaj.gov.br

Link para o currículo Lattes: http://lattes.cnpq.br/1532922752008435

Erica de Souza Silva: Universidade de Pernambuco, Recife, PE, Brasil.

E-mail: erica.souzasilva@hotmail.com

Link para o currículo Lattes: http://lattes.cnpq.br/9745321608147287

Patrícia Alves da Silva: Universidade de Pernambuco, Recife, PE, Brasil.

E-mail: patricia_alves12@hotmail.com

Link para o currículo Lattes: http://lattes.cnpq.br/6432397813954062

Data de submissão: 30 de maio de 2012

Data de recebimento de correções: 31 de março de 2014

Data do aceite: 31 de março de 2014

Avaliado anonimamente 